\title{
The Influences of Employees' Emotions and Cognition on IT Adoption: Some Perspectives from Iran
}

\author{
Armin Kashefi \\ Brunel University \\ armin.kashefi@brunel.ac.uk
}

\author{
Dr Pamela Abbott \\ Brunel University \\ pamela.abbott@brunel.ac.uk
}

\begin{abstract}
This paper presents an extended model of individuals, reactions to IT implementation initiatives. The aim is to explore the relationship between an employee's cognitive appraisal of an IT initiative, their emotional response and the processes they undergo when faced with difficulties in accepting IT adoption and change in an organizational setting. The paper presents the results of an interpretive case study based in Iran. According to the findings of the study, employees' evaluations of a new IT initiative can become an obstacle to change. The paper's first contribution is to provide a deeper understanding of the effects of an IT implementation on individuals, emotions and cognition. The second contribution is the use of the extended model in a real organizational setting in Iran, a country in which the importance of employee's reactions to technology change has never been considered as crucial.
\end{abstract}

\section{Introduction}

Information Technology and Systems (IT/IS) have now become ubiquitous in the developed world. Information Systems encompass such diverse areas as agriculture, manufacturing, services, education, medicine, defense and government [32][25]. Over the past two decades of IS research the focus has shifted to encompass the relationship between IS and organizations as a whole. Relevant issues include communication and collaboration between people and organizations, inter organizational systems, and the effect of IT related change in organizational settings [25]. Research on organizational change has shown that change programs frequently face a series of problems [14]. Related research in IS, has consequently highlighted the importance of social issues related to computer-based IS [32]. This has led some IS researchers to adopt empirical approaches which focus particularly on human interpretations and meanings [32].

Inevitably, the introduction of a new IT generates a multitude of expected and unexpected consequences in the users' environment [1]. These consequences are interpreted and understood in a variety of ways by users, triggering complex user responses. Different theoretical perspectives have identified diverse obstacles to change in such situations. For instance, the tendency to hold onto old ways of doing things has been perceived to be a major problem by top management [14]. To date, however, little attention has been given to understanding how emotions can influence employees' IT adoption and use. Emotions influence our beliefs and attitudes and they help guide our thinking, decision-making and actions [21]. Additionally, cognitive-based models (e.g. technology acceptance model [9][10], the unified theory of acceptance and use of technology [31], etc.) are thought not to be able to capture the full range of emotional reactions of users in order to account for their relationship to IT adoption [2]. This has left scope for integrating psychological perspectives into the domain of IS to explore the relationship between employees' perceptions and interpretations of technology, their emotional response and their consequent adoption of technology.

This paper focuses on employees' responses to IT implementation (instead of organizational change in general) in a government organization in Iran, and the emphasis will be exclusively on the adoption of technology by employees. The purpose is to examine the individuals' reactions to change by exploring the relationship between employees' emotions and cognition that contribute to their IT adoption and use. Thus, the paper will address the following question: "How do different stimuli during an IT implementation influence employees' emotions and cognition toward their technology adoption?" The paper has a twofold contribution to the field of IS associated with psychology. The first contribution is that it allows a 
better understanding of individuals' IT adoption by going beyond cognitive-based models and focusing on employees' psychological perspectives. In doing so the intention is to fill in the current gap in this area to some extent and explore the consequences of employees' cognitive and emotional experiences in a larger framework. The second contribution is the use of the extended model in a real organizational setting. In other words, to date, only a few articles have partially referred to these theories and models, combined them with psychological perspectives and used them in practice in a qualitative and interpretive way in the field of IS. Most studies conducted to date have been quantitative with the aim of measuring or predicting behavior. Furthermore, this investigation has been carried out in Iran, where little research of this nature has been conducted due to a variety of reasons. Additionally, much of the work done up to now about this country has focused primarily on technical aspects of IT implementation and development with little emphasis placed on the importance of employees' perspectives and interpretations of these implementations.

The remainder of the paper is organized as follows. The following section reviews the research on employees' personal changes, their emotions and the sense making process associated with IT implementations. Next is the theoretical framework section, which focuses on an extended model of individual's reaction to IT implementation initiatives. The research method is next described followed by the case study. The paper ends with a discussion of the results, conclusion, contribution for research and practice and suggestions for further research.

\section{Personal Change, Employees' Emotions and Making Sense of IT}

Though something might be gained by a change, something will also be lost in it. Robbins \& Finley [29], when reviewing three kinds of change (global change, organizational change and personal change), put emphasis on the personal change and describe it as "little and micro changes that assail us on an individual level" (p.42). Eriksson [14] similarly indicates that all people who are affected by change will experience some emotional turmoil. Bovey \& Hede [4] also stress that letting go of the old ways of doing things is not only a cognitive process, but is first and foremost, a sequential emotional process. Employee's personal change, hence, has become an important aspect of research in the domain of IS associated with psychology, where a range of strong positive attitudes to strong negative attitudes has been identified concerning their receptivity to change [28][14]. Regarding employees' response to change, Clarke [8] stresses that people are different in their reactions to change. Some employees passively resist it such as agreeing verbally but withholding information. Others still embrace it while some oppose the change actively. In addition to this, rumors and background conversations regarding the change and future of both the organization and employees compound the difficulty of accepting the change [7][12][15].

The fact is, a proper acceptance of IT-related change by employees necessitates them to be personally altered to some extent and adopt new ways of doing things. This implies that they have to experience the stages of personal change. Bridges [6] conceptualizes these types of transition into three overlapping stages divided by clear boundaries, as beginning with an ending and then going on to a new beginning via a neutral phase (also referred to as the transition phase). Moreover, Clarke [8] points to employees' pain levels and elucidates that these are usually highest in the early stages of personal change as people move from accepting the end of the past into the transition phase. This stage often gives rise to negative emotions among employees [20]. These undesirable emotions experienced by most employees can be categorized into four major groups: stress, uncertainty, fear and anger, however, the first two are considered significant [24][20][30]. On the other hand, positive emotions such as enjoyment, pleasure and happiness have, however, often been referred to in IS studies [10][17].

In all situations of new IT initiatives, however, employees have to make sense of the IS/IT [22][26][28][15] in organizations in order to welcome the technology, go through personal change, cope with new practices regarding particular instances of IS/IT innovation and finally mobilize towards it [14]. With regard to this, Orlikowski \& Gash [26] argue that an understanding of peoples' (employees') interpretations of a technology is critical to understanding their interaction with it. In this sense making process, people develop particular assumptions, expectations and knowledge of the technology that help to shape their subsequent actions toward it. Cognition and microlevel processes at the individual level are therefore keys to understanding the impact of new technology in any IT-related organizational change [22][26][16]. Despite the fact that these interpretations of technology become evident and are rarely reflected on, they remain significant in influencing how actors in organizations think about and act toward technology [14][26]. In other words, little is known on the topic under investigation in the domain of IS associated with psychology and therefore the resulting gap can be 
addressed at least partially through this study. That is, an understanding of how employees' emotions and cognition influence their receptivity toward technology adoption can assist the development of a contextualized professional practice [23], which is the main motivation for conducting this study.

To conclude, in this section the paper briefly reviewed and covered important topics concerning IS/IT related organizational change from a psychological perspective. In the following section the theoretical framework provides further details about how change initiatives could be divided into their critical components.

\section{Theoretical Framework}

This paper presents an extended model of individuals' reactions to IT implementation initiatives. This model is based on Huy's [16] change dynamics model at the individual level and its integration with Lazarus's [19] stress theory (Figure 1). Although the former model was proposed by Huy [16] and its likely connection with stress theory was implied alongside the explanation of that model, until recently there have been relatively few studies, in an organizational context, explicitly based on this integrated model. This holds true specifically for studies in the domain of IS associated with psychology which seek to use these concepts jointly for better understanding of employees' technology adoptions from a psychological perspective. For instance, Eriksson [14] drew on Huy's model solely in order to explore the relationship between change and emotion by focusing more on organizational change as a whole. Unlike that approach, this paper will provide insight into individuals' emotions and cognition with regard to IT adoption by integrating Huy's [16] model with Lazarus's [20] stress concepts and using the integrated model as a theoretical lens to explore that relationship explicitly.

The main reason for using the combined model is to take advantage of both concepts jointly. To put it simply, the first model (Huy's dynamic model of change) divides the change process into its three critical components (receptivity, mobilization and learning) and shows clearly how individuals go through the course of change. The second model (Lazarus's stress theory) demonstrates how individuals' primary appraisals (subjective judgments about the significance of a specific event) and secondary appraisals (personal evaluations of coping resources, constraints and options) affect their receptivity to and mobilization for change $[16][18][21]$. The joint use of these models allows for a greater understanding of employees' emotions related to their perceptions and interpretations of change and consequent reactions. As such, this approach is consistent with Eriksson's [14] notion that "a person's cognition, emotion and actions are intimately interlinked" (p.113), that is, cannot be easily separated, but need to be studied as an integral whole.

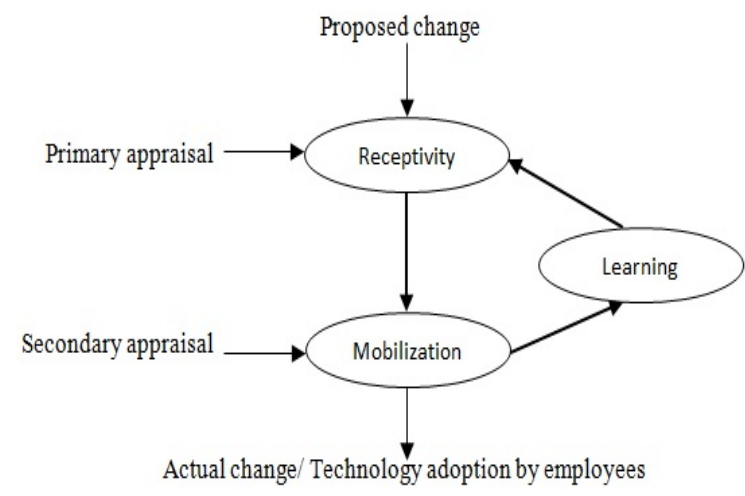

\section{Figure 1. An extended model of individual's reaction to IT implementation initiatives}

This model gives insight into how changes in employees' emotions and their evaluations of a situation during and after an IT implementation could dramatically affect those three components toward the realization of change. Most literature in this domain either mainly concentrates theoretically and quantitatively on the variety of emotions and perceptions that individuals/employees usually have during organizational change initiatives [18][19][20][21] while few point to the importance of earlier mentioned change components [16]. However, the relationship between the experienced emotions by employees and the steps (receptivity, mobilization and learning) in which they have difficulty in realizing change has remained unclear. As a result, this study differs from prior research in that the extended model is intended to redress that imbalance and explore that relationship. It is also noteworthy to stress that although concepts such as emotions and feeling are distinct [13], this study, in order to avoid confusion, adopts Eriksson's [14] approach and generally uses the concept of emotion since it is not critical for the purpose of this study to distinguish the subtler differences among the terms.

In this model, receptivity refers to employees' willingness to consider change and recognize the legitimacy of such proposals. Receptivity as a process shapes and is shaped by the continuous sense making and sense giving activities conducted among various members of an organization [16]. This phase is highly affected by primary appraisal (the first step of Lazarus's stress theory), which is about employees' 
assessment of the significance of a new event for their own well-being. Since emotions are reactions to the meaning of a situation [21] and that meaning is due to an individual's evaluation of a situation [20], the receptivity phase covers both employees' emotional and cognitive responses.

However, unlike receptivity, mobilization is the concrete actions taken by a person (employee) in the direction of change (adoption and use of IT) [16]. As it implies, mobilization covers the action part of the change process in which employees take steps toward change. Mobilization depends on the time and receptivity of others, support structures, systems and skills. Moreover, mobilization is greatly dependent on the receptivity phase. With regard to the Lazarus' stress theory, mobilization is affected by secondary appraisal, which refers to employees' evaluations of their own resources and capabilities for dealing with the stressor [19][20][21]. The mobilization phase is critical in moving toward technology adoption, since the main challenge for individuals is often not a problem of choosing cognitively but of taking tangible actions. Those actions mainly derive from employees' strong motivations and commitments to complete the achievement regardless of great difficulties [16].

Regarding the learning phase, since employees learn from their earlier experiences, this step may affect their willingness to see the need for change and to mobilize accordingly.

Concerning cognition in individuals, the appraisal process involves primary and secondary appraisals jointly. To put it simply, for the purpose of analysis they are considered separately, however primary and secondary appraisal go hand in hand as one evaluates the importance of the event while the other one assesses the available resources and appraises the coping mechanisms. They both happen together, or sometimes secondary appraisal occurs first and affects primary appraisal and one's motivation [21]. As to motivation, it refers to means, ends and cognitive concerns that are identified as goals in individuals [18]. Nonetheless, overlaps between motivation, cognition and emotion make it difficult to separate and distinguish their respective territories [19].

\section{Methodology}

A broadly interpretive approach was adopted in this study [33] with the aim of understanding the context of the IS and the processes whereby the IS influences and is influenced by the social context [32]. A case study approach was selected since it enables multiple methods of data collection to gather information from one or a few entities such as people, groups, or organizations [3][34]. The research was carried out in Iran in a government organization named the 'P.E. Organization'. This name is a pseudonym and used for protecting the confidentiality of this organization. The study was exploratory in nature [34] with the aim of understanding how employees' emotions and cognition were related to their adoption of IT.

Data was collected by one of the authors, an Iranian citizen, who was introduced to the participants as a researcher. Data collection was conducted via semistructured interviews and document analysis. However, some participants were unwilling to have their conversations tape-recorded in spite of the assurance of confidentiality presented to them. Hence, in those cases, note taking was substituted for tape-recording. Questions focused on exploring employees' different perspectives regarding the effects of IT-related organizational change on their emotions and behaviors. In-depth interviews were held with 10 middle-aged employees ( 5 male and 5 female). It was decided to interview employees within the age range of 50 since people in this age group are more likely to: persist in old habits; be significantly affected by new IS/IT initiatives; and be more often associated with apparently stable and therefore unchangeable personal characteristics [13]. Older employees are said to participate less in educational programmes and training activities [29]. Each interview lasted approximately one hour, and was conducted within a month during the research fieldwork. Each interview was first transcribed verbatim into Persian (the national language of Iran) and then translated into English as accurately as possible.

Data were identified, analyzed and reported using the six phases of thematic analysis [5]: (1) becoming familiar with the data (2) generating initial codes (3) searching for themes (4) reviewing themes (5) defining and naming themes and (6) producing the report.

\section{Case Study}

The case study organization has both responsibility and authority for all aspects of sport-related events and issues throughout Iran. It was selected for this research because it underwent three organizational changes over the past three decades, which is significant when compared to other government organizations in the same period. In the first two organizational changes, the structure was transformed whereas in the last one computerized work systems (new IT initiatives) were introduced. Amongst all the organization's divisions, the Department of Sport's (also a pseudonym) development programme and budget were selected for the purpose of this paper since it was one of the core 
departments for computerizing the work system. Moreover, this unit had the criteria stated earlier (older employees) which matched the study's requirements. As to the nature of the employees' work, this division is responsible for planning and forecasting the budget for every sport federation in the capital and other cities. Moreover, employees in this sector had to have good computer skills in order to perform their jobs properly, even if they came from different educational backgrounds.

Prior to the new IT initiative, work processes were completely paper based and manually driven. The organizational structure was changed twice in order to improve the workflow but the outcome was not as effective as expected. Workflow issues included managing information flows and communication with other organizations especially international ones, however, at the individual level employees were happy with their routines. Although the work processes were not fast and effective, there were no complaints.

After two structural changes within this organization, management suddenly decided to introduce IT to the organization in order to automate the workflow and also to expand their communication with other organizations nationally and internationally. Concerns, however, arose at this point, as management had no clear strategies toward IT implementation and use. In other words, although at the beginning the aim was to increase the pace of information flow and efficiency within the organization, their ambiguous strategies and the consequences of those ambiguities prevented the organization from implementing the system successfully. Such ambiguous strategies included: the absence of definite milestones for IT implementation progress; adherence to traditional managerial approaches which were unfavorable to computerized work systems; and allocating inadequate budgets for effective implementation and employee training. These resulted in slow uptake of the system by employees.

Based on thematic analysis of the interviews, four major themes were carefully identified to be of concern namely: (1) technical difficulties of computerized system, (2) inadequate training, (3) rumors, and (4) management's unclear strategies. It was perceived that these themes were the main concerns amongst employees and had influenced their emotions and evaluations of the computerized work system and consequently their IT adoption. Furthermore, and despite some overlaps in respondents' views and comments, the employees' explanations also revealed three dominant perspectives they had about the IT initiative. The first we have named the mainstream view, that is, that IT implementation and use were undesirable. These employees were unhappy and had negative evaluations and emotions regarding the use of the new system with reference to the four earlier-stated concerns. The second dominant perspective we named middle-of-the-road, since no specific supportive attitudes nor negative evaluations of the situation were expressed by this group. To put it simply, they were impartial. However, a number of respondents were happy about the new automated work system despite the difficulties stated earlier and had used the system to some degree. This group we have named optimistic since they represent an affirmative perspective. It is also noteworthy to mention that between the second and third perspectives (impartial compared to affirmative) some overlaps were also observed. In the following section each of those four main concerns based on the employees' three perspectives (undesirable, impartial and affirmative) will be briefly reviewed.

\subsection{Technical Difficulties of Computerized System}

Almost all of the respondents had negative evaluations concerning the technical part of the implementation (including both hardware and software) that had caused them to experience diverse emotions. As such, one of the respondents mentioned:

"Wasn't it irrationally? When the system was not ready and not reliable why so much pressures to use it? What about the motivation we were supposed to have? When you see no support, lots of technical difficulties and no proper training, then who cares about the new system? It just made everyone angry, when you were for example in the middle of something and recognized that the task you were working on had not been saved..." (Employee C)

In contrast and in a neutral way another interviewee responded:

"It was obvious for me that the system would not work even reasonably, no proper training and lots of technical difficulties, and no clear strategies... I don't know why my colleagues were angry about it, I didn't really rely on the system and instead I did my tasks in the traditional way [paper work] ..." (Employee A)

In a more positive way one of the interviewees added:

"The traditional work system was slow, but the new system was faster despite the regular and often frustrating technical difficulties it had, end of the day it was ok and I accepted it that way, when you are on your own you have no motivation, but it wasn't too bad" (Employee D)

And similarly, another employee replied: 
"The system was slow anyway but I was happy with it, I was in no rush to handle all my tasks in a single day so instead of one day I spent four days on tasks but with no pressure, it was ok..."(Employee B)

\subsection{Inadequate Training}

Concerning the training, management had provided only some of the employees with computer training and others in the department were left on their own. This decision had been made to push the system forward quicker but instead had negative effects on both groups. Those who were involved in training had no computer knowledge and consequently experienced too much pressure to first learn how to use computers and then the computerized work system. Those who were not involved had observed the situation and made negative evaluations about it. One employee involved in the training mentioned:

"If computerizing the work system was necessary for our department, why would they choose only some of us? It was not fair; we were under pressure for learning the system while our colleagues were happy with doing their old routines!" (Employee I)

And:

"This caused me too much stress, I had to attend training class after work hours and learn how to use computer on top of my daily routines. It took my energy and it was frustrating, I was like emotionally tired and rationally could not find any reason for implementing such this system" (Employee C)

However, employees who were not involved in training commented:

"I was like middle-of-the-road about the training and learning the computer, indifference somehow, because firstly there was no pressure on me compared to my colleagues who were trained and secondly I was not interested to be trained anyway because the system was often down and it had just one meaning; having loads of tasks in hand to do in traditional way..." (Employee F)

And in a pleased way:

"To me the content and number of training sessions although were not excellent but I could say they were ok and I learned a lot. I wanted to learn the computer anyway and I was happy with those sessions because I could use the computer at home as well" (Employee B)

\subsection{Rumors}

According to interviewees' comments the importance of rumors and background conversations of change as a main source of creating negative attitudes towards change should be also taken into account by managers in advance since all the interviewees considered these conversations as problematic. Concerning the effects of rumors and background conversations, one of the interviewees mentioned:

"Rumors were the annoying part of the story because no one had any information about what was happening and you could hear two completely different rumors in less than half an hour!" (Employee J)

\subsection{Management's Unclear Strategies}

Lack of support was another big issue for employees since after a few months they realized that management was not as eager as they were at the beginning about the IT implementation. Noticeably, the respondents' comments had negative overtones and were plaintive. For instance, one of the interviewee stressed:

"When they themselves [management] had no clear idea about the implementation and automating the system, why would we trust this system? It was disappointing, I was stressed but what could be done about it? When you see no motivation in management, you lose your motivation as well. When you see you don't have the needed resources it affects everything, your emotion, your evaluation of that event, everything" (Employee H)

However, a more neutral response came from another interviewee:

"I didn't expect them to act professionally so to me it was ok; I was indifferent from the beginning, you could not expect more from them when you knew their [management] way of thinking” (Employee A)

Additionally, lack of communication between top management and employees regarding the IT initiative was another problem and had created countless background conversations about the future of both the organization and employees resulting in further stress. The findings of this empirical research also reveal that from the employees' (both men and women) point of view, individual concerns (e.g. job security, base salary rate etc.) always take first place over social and organizational issues since individual concerns are highly related to employees' personal lives. Social concerns were the second most important concerns and organizational issues had the least important to them.

The aim of this research was to examine the individuals' reactions to IT-related organizational change by exploring the relationship between employees' emotions and cognition that contribute to employees' technology adoption and use. It is assumed that negative comments derive from employees' 
negative emotions about the situation stemming from their negative evaluations of the IT implementation and use. Interviewees, in reply to the question regarding causes of these emotions, mentioned that they were involuntarily experiencing various thoughts in different phases of the implementation and, therefore, did not have peace of mind to think about other things. They point to these periods as "stressful moments" and "the worst moments". One of the interviewees explained the consequences of those stressful moments on herself:

"I was feeling stressed because I was not ready to learn the computer at that time, I could not concentrate on it, I felt I had no support, my mind was busy with other things and my receptivity was zero to be honest, but when I managed to learn I had no motivation to take steps toward it, several things were wrong" (Employee I)

Moreover, according to the respondents, employees accepted the system passively such as agreeing in words but not following through due to their negative evaluation and lack of motivation. By motivation it means (according to interviewees' comments) employees perceived there were no point in using the system with all those hardware and software difficulties, no proper training and on top of it, lack of management support.

\section{Discussion}

Organizational change process in general, IT implementation, in particular, and specifically the course of IT adoption by employees, which is the focus of this paper, needs to be understood more from the employees' perspective than from the management's. An employee-centered standpoint considers the worker less as a tool and more as a human per se in the contribution to the success of an organization. This discussion is organized according to the respondents' three perspectives concerning the adoption of the IT initiative, namely: undesirable, impartial and affirmative. The intention here is not to merely objectively refer to comments as positive/ negative or to specify 'only true appraisals or emotions' in a change process. Rather, the intention is to gain a better understanding and be able to describe what kinds of appraisals and emotions employees had by classifying them into three subjective themes and then exploring the effects of each theme on receptivity, mobilization and learning based on the theoretical framework.

With regard to the respondents' undesirable perspectives, employees' motivations and perceptions were affected mostly negatively by different stimuli (e.g. rumors, lack of management support etc.). Those undesirable evaluations of the situation consequently affected employees' willingness directly and generated negative emotions [20][21] concerning their technology adoption. Negative evaluations made employees not to be mentally ready and motivated (receptivity phase) in order to take concrete actions (mobilization phase) toward the adoption and use of the new computerized work system. Now by referring back to the theoretical framework and the meaning of the receptivity, mobilization and learning phases and their integration with primary and secondary appraisals, these relationships can be better explained. To put it more simply, employees who had negative attitudes toward the IT implementation and adoption had negative evaluations about both personal concerns $[14][18][21]$ (primary appraisal) and available resources (secondary appraisal) [21]. The receptivity phase, as stated earlier, is affected by the primary appraisal and the mobilization phase is influenced by the secondary appraisal [16].

Primary appraisal is also concerned with the individuals' well-being [18][19][21]. Since nearly most of the emotional obstacles employees experienced concerning their technology adoption and use were about personal concerns, it can be assumed that primary appraisal may have limited employees' receptivity. In other words, their negative evaluations and emotions, complicated by learning from two previous unsuccessful organizational changes that made them think nothing would work in that organization, influenced the receptivity phase. Similarly, employees' secondary appraisal made negative evaluations of the situation (i.e. lack of available resources to cope with the new system as well as their lack of control over the situation), thus intensely and negatively affecting the mobilization phase and employees' attitudes. In this case, employees who were primed for the mobilization phase, found it disappointing when they realized the technological difficulties of the computerized system and the lack both of proper training sessions and support from management, amongst other issues. Those difficulties made them, therefore, unmotivated to take tangible actions toward the adoption of IT. Those negative appraisals jointly caused employees not to make sense of the technology [26] properly and doubted the legitimacy of change, thus making the transition from receptivity to mobilization very painful for them.

In brief, the mainstream concerns about the technology adoption occurred during the receptivity phase. The reason could be that while people still have concerns at the cognitive level, and cannot view change as an opportunity, negative appraisals about both their personal concerns and lack of available resources may result in negative emotions. Those 
perceptions may make employees less receptive and unable to mobilize and act in a changed way. Accordingly, those with negative appraisal (primary and secondary) also held negative emotions, were demotivated and less receptive and could not make sense of the computerized system in order to mobilize. Latterly, the linkage between the receptivity phase and mobilization became loose and, since there was no learning due to passive acceptance of the computerized system by employees, very little progress was made. Moreover, consequent emotions, thoughts and evaluations made the receptivity phase even more complicated to the extent that some of the respondents mentioned that their receptivity levels were almost zero.

As to the impartial perspectives, respondents who were middle-of-the-road, did not have negative evaluations of the situation compared to the above discussion about their personal concerns, consequently did not have intense negative emotions about the IT implementation and adoption as such. Nevertheless, even those disinterested respondents still did not have enough motivation and were not cognitively persuaded to mobilize toward the adoption of technology (to move from receptivity to mobilization). To put it more simply, although employees perceived that the situation was not stressful, it still was not congruent with their goals (doing their daily routines), and thus they lost their motivation and became less receptive. Simultaneously, they appraised that they also did not have the required resources such as management support and a reliable system and more importantly, had no control over the situation. Therefore, those assessments made employees even less receptive and demotivated toward adopting and using the technology. As mentioned earlier these primary and secondary appraisals go hand in hand as one evaluates the importance of the event while the other one assesses the available resources and evaluates the coping mechanisms. With regard to the learning stage, and similar to the 'undesirable' perspective, employees preferred to cope with the situation by doing nothing and using the policy of "wait and see" rather than learning from the outcomes of their actions. As a result, they accepted the new system passively and were reluctant to work with it. The linkage between the receptivity phase and mobilization step became loose and since there was no learning very little progress was made.

Concerning affirmative perspectives, respondents had appraised the new automated system positively, were happy, and used it although not completely. Moreover, they were motivated about using the new system and had mobilized toward the adoption of technology accordingly. The reason behind their actions, according to the interviewees, stem from their positive evaluations of the situation that subsequently generated positive emotions and therefore persuaded them to take steps (to some extent) toward the IT adoption.

To summarize, when both primary and secondary appraisals result in negative evaluations, those perceptions trigger intense negative emotions, such that employees become demotivated and less receptive and are not able to mobilize and learn ('undesirable' perspective). However, when, for example, primary appraisal is more amenable, but secondary appraisal is undesirable (as was the case in the 'impartial' perspective), it still can negatively influence the employees' cognition, motivations and receptivity and result in demotivation and passivity towards mobilization. On the contrary, when there is no personal concern at stake and resources are considered as sufficient (even to some degree), employees will have the motivation to mobilize and take tangible actions ('affirmative' perspective). Here, the link between receptivity and mobilization was stronger, some learning occurred and greater progress was made.

\section{Conclusion}

As mentioned at the beginning, the first contribution of this paper is to offer a better understanding of individuals' technology adoption by exploring the employees' psychological perspectives in relation to their cognitive and emotional experiences in a larger framework. The second contribution is the use of the extended model in a real organizational setting.

Regarding the first contribution, the literature review and findings of the empirical study jointly help to illuminate relationships between different stimuli and employees' cognition, emotions and motivation. By using the theoretical framework as a lens to help understand this complex social phenomenon, it can be argued that individuals' evaluations (cognition) of an IT initiative and resulting emotions play a significant role in the receptivity phase. It can also be argued that successful technology adoption by employees requires management's attention to stimuli that may affect employees negatively. In the case study organization, however, little thought was given to those concerns.

As to the second contribution, little research of this nature has been conducted and little reference made to these theories and models in the field of Information Systems. This extended model, taken from the field of Psychology, demonstrates, on the one hand, the psychological factors, processes and complicated interrelated relationships inherent in change processes 
and on the other hand, the stages at which the change process encounters issues.

This paper has sketched out the ways in which employees' emotions and cognition can be disrupted due to different stimuli as a consequence of implementing new IS/IT. The findings suggest implications for practice as well as directions for future research. Understanding how employees' emotions and cognition considerably affect their technology adoption is critical for successful IT implementation and use in organizations. These results could assist decision makers in assessing IT adoption concerns at each phase of the change process and the intensity of the concern. This insight stems from realizing how employees make sense of the IT, how they interpret it and how they go through personal changes and are affected psychologically. In the organization discussed above decision makers did not have the awareness of those critical phases (receptivity, mobilization and learning) and the impact of employees' emotions and evaluations on their technology adoption. In retrospect, they could have realized the difficulties, provided employees with more resources to cope, and more importantly addressed their intense emotions and negative evaluations of the situation.

We conclude by reviewing the research question, "How do different stimuli during an IT implementation influence employees' emotions and cognition toward their technology adoption?" It can be argued that there is no simple, single and individual reason behind reduction in employees' motivation and their 'not positive' evaluations of IT implementation. By 'not positive', we point to both negative and neutral comments received from respondents. These perceptions resulted in a loose linkage between receptivity and mobilization since there was no learning due to passive acceptance of the computerized system by employees. For example emotional unhappiness and undesirable evaluations (receptivity phase) caused employees not to mobilize properly (mobilization phase) and learn new IT skills that ultimately resulted in poor organizational coordination. Subsequent emotions, thoughts and evaluations made the receptivity phase more complicated to the degree that some of the respondents mentioned that they experienced no receptivity at all. In fact, there are varieties of evaluations (appraisal) that affect one's emotion and motivation that jointly, make employees less receptive and not to be able to mobilize properly toward the realization and adoption of change. In the case discussed above, managers considered the implementation as successful since computers were placed in the organization. Lack of understanding employees' perceptions and emotions about the computerized system, however, suggests instead that technology adoption was not successful at the time of the IT implementation.

\section{Limitations and Further Research}

This study has limitations that should be acknowledged. The first and foremost limitation was in its scope since this study focused on one single case study in a government organization in Iran under severe time limitations. Furthermore, it relies on a small amount of participants. The results therefore are not generalizable, nor are they expected to confirm or explain extant theory. Rather, the case represented an opportunity to explore the processes through which emotional response to change are realized, albeit using a unique situation. There is room for undertaking a longitudinal study with more in-depth interviews on the basis of the current results to provide more insight on the role of emotion, cognition and psychological factors on employees' IT adoption and use. Also, large-scale studies involving numerous users would help assess the model's generalizability to other contexts such as private firms. The next limitation was the selection of employees in the age range of 50. To gain a less subjective response, participants in any future study would need to include a range of ages to provide data for more insightful results on this topic. Besides, more research needs to be done to investigate the effects of political and social factors (e.g., group norms, organizational culture, and colleagues' attitude) on employees' IT adoption and user adaptation strategies about this country as it continues to expand the use of IT and to automate the organizations' work systems.

\section{References}

[1] Beaudry, A., and A. Pinsonneault, "Understanding user response to information technology: a coping model of user adaptation”, MIS Quarterly, 2005, 29 (3), pp.493-524

[2] Beaudry, A., and A. Pinsonneault, "The other side of acceptance: studying the direct and indirect effects of emotions on information technology use", MIS Quarterly, 2010, 34(4), pp.689-710

[3] Benbasat, I., D.K. Goldstein, and M. Mead, "The case research strategy in studies of information systems", MIS Quarterly, 1987, 11(3), pp.369-386

[4] Bovey, W.H., and A. Hede, "Resistance to organisational change: the role of defence mechanisms", Journal of Managerial Psychology, 2001, 16(7), pp. 534-548 
[5] Braun, V., and V. Clarke, "Using thematic analysis in psychology", Qualitative Research in Psychology, 2006, $3(2)$, pp.77-101

[6] Bridges, W., Managing transitions: making the most of change, reading, MA: ADDISON-Wesley, 1991

[7] Caldwell, D.F., and C.A. O'Reilly III, "Responses to failure: the effects of choice and responsibility on impression management", Academy of Management Journal, 1982, 25 (1), pp. 121-136

[8] Clarke, L., The essence of change, 1st edn. Buckley A, ed. Hemel Hempstead: Prentice Hall Europe, 1994

[9] Davis, F. D., "Perceived usefulness, perceived ease of use, and user acceptance of Information Technology", MIS Quarterly, 1989, 13(3), pp. 319-340

[10] Davis, F.D., R.P. Bagozzi, and P.R. Warshaw, "Extrinsic and intrinsic motivation to use computers in the workplace", Journal of Applied Social Psychology, 1992, 22(14), pp. 1111-1132

[11] Dedrick, E., and G. Dobbins, “The influence of subordinate age on managerial actions: an attributional analysis", Journal of Organizational Behavior, 1991, 12, pp.367-378

[12] Dent, E., and S. Goldberg, "Challenging resistance to change", The Journal of Applied Behavioral Science, 1999, 35 (1), pp. 25-41

[13] Ekman, P., and R.J. Davidson, The nature of emotion: fundamental questions, Oxford University Press, New York, 1994

[14] Eriksson, C.B., "The effects of change programs on employees' emotions", Personnel Review, 2004, 33 (1), pp. 110-126

[15] Ford, J.D., L.W. Ford, and R.T. McNamara, "Resistance and background conversations of change", Journal of organizational change management, 2002, 15(2), pp. 105-121

[16] Huy, Q.N., "Emotional capability, emotional intelligence and radical change", Academy of Management Review, 1999, 24 (2), pp. 325-345

[17] Kim, H.W., Y.P. Chan, and S. Gupta, "Understanding the balanced effects of belief and feeling on information systems continuance", ICIS 2004 Proceedings, Paper 24

[18] Lazarus, R.S., "Constructs of the mind in adaptation", In: Stein, N., B. Leventhal, and T. Trabasso, Psychological and biological approaches to emotion, New Jersey, Lawrence Erlbaum Associates, 1990

[19] Lazarus, R.S., "Cognition and motivation in emotion", American Psychologist, 1991a, 46(4), pp. 352-367
[20] Lazarus, R.S., "From psychological stress to emotions: a history of changing outlook", Annual review of psychology, 1993, 44 (1), pp. 1-21

[21] Lazarus, R.S., and S. Folkman, Stress, appraisal, and coping, Springer, New York, 1984

[22] Liu, Y., and P. Perrewe, "Another look at the role of emotion in the organizational change: a process model", Human Resource Management review, 2005, 15, pp.263-280

[23] McGrath, K., "Affection not affliction: the role of emotions in information systems and organizational change", Information and Organization, 2006, 16(4), pp. 277-303

[24] Milliken, F.J., "Three types of perceived uncertainty about the environment: state, effect and response uncertainty", Academy of Management Review, 1987, 12 (1), pp. 133-143

[25] Myers, M., and D. Avison, Qualitative research in information systems: a reader, London: Sage, 2002

[26] Orlikowski, W. J., and D.C. Gash, "Technological frames: making sense of information technology in organizations", ACM Transactions on Information Systems, 1993, 12(2), pp. 669-702

[27] Perry, E.L., C.T. Kulik, and J. Zhou, "A closer look at the effects of subordinate-supervisor age differences", Journal of Organizational Behavior, 1999, 20, pp.341-357

[28] Piderit, S.C., "Rethinking resistance and recognizing ambivalence: a multidimensional view of attitudes toward an organisational change", Academy of management Review, 2000, 25 (4), pp. 783- 794

[29] Robbins, H., and M. Finley, Why change doesn't work, why initiatives go wrong and how to try again and succeed, London: Orion Business Books, 1997

[30] Vakola, M., and I. Nikolaou, "Attitudes towards organisational change: what is the role of employees' stress and commitment?", Employee Relations, 2005, 27 (2), pp.160- 174

[31] Venkatesh, V., M.G. Morris, G.B. Davis, and F.D. Davis, "User acceptance of Information Technology: toward a unified view", MIS Quarterly, 2003, 27(3), pp. 425-478

[32] Walsham, G., Interpreting information systems in organizations, England: John Wiley and Sons Ltd, 1993

[33] Walsham, G., "Doing interpretive research", European Journal of Information Systems, 2006, 15, pp. 320-330

[34] Yin, R. K., Case study research: Design and methods, 4th edn, Thousand Oaks, CA: Sage, 2009 